\title{
BMJ Open Ibandronate to treat skeletal-related events and bone pain in metastatic bone disease or multiple myeloma: a meta-analysis of randomised clinical trials
}

\author{
Chun-Jing Geng, ${ }^{1}$ Qian Liang, ${ }^{2}$ Jian-Hong Zhong, ${ }^{3}$ Min Zhu, ${ }^{1}$ Fan-Ying Meng, ${ }^{4}$ \\ Ning Wu, ${ }^{1}$ Rui Liang, ${ }^{1}$ Bin-Yi Yuan ${ }^{5}$
}

To cite: Geng C-J, Liang Q, Zhong J-H, et al. Ibandronate to treat skeletal-related events and bone pain in metastatic bone disease or multiple myeloma: a meta-analysis of randomised clinical trials. BMJ Open 2015;5:e007258. doi:10.1136/bmjopen-2014007258

- Prepublication history for this paper is available online. To view these files please visit the journal online (http://dx.doi.org/10.1136/ bmjopen-2014-007258).

C-JG, QL and J-HZ contributed equally.

Received 24 November 2014 Revised 27 March 2015 Accepted 9 April 2015

CrossMark

For numbered affiliations see end of article.

Correspondence to Professor Rui Liang; gxzlyyliangrui@163.com, and Professor Bin-Yi Yuan; gxyuanbinyi@163.com

\section{ABSTRACT}

Objective: Randomised controlled trials (RCTs) have given contradictory results about the efficacy and safety of ibandronate in treating metastatic bone disease (MBD) or multiple myeloma. This review metaanalysed the literature to gain a more comprehensive picture.

Design: Systematic review and meta-analysis of ibandronate compared with placebo or zoledronate.

Data sources: PubMed, EMBASE and the Cochrane Library databases were systematically searched to identify RCTs published up to March 2015 evaluating ibandronate to treat MBD or multiple myeloma.

Review method: 10 RCTs involving 3474 patients were included. Six RCTs were placebo-controlled and four compared ibandronate with zoledronate. The studies included in this review were mainly from European countries.

Results: Intravenous ibandronate $(6 \mathrm{mg})$ or oral drug $(50 \mathrm{mg})$ decreased the risk of skeletal-related events compared to placebo (risk ratio (RR) 0.80 , $95 \% \mathrm{Cl} 0.71$ to $0.90, \mathrm{p}=0.002$ ). It also reduced the bone pain score below baseline significantly more than did placebo at 96 weeks (weighted mean difference $-0.41,95 \% \mathrm{Cl}-0.56$ to $-0.27, \mathrm{p}<0.001)$. The incidence of diarrhoea, nausea and adverse renal events was similar between the ibandronate and placebo groups, but ibandronate was associated with greater risk of abdominal pain. Ibandronate was associated with similar risk of skeletal-related events as another bisphosphonate drug, zoledronate (RR 1.02, $95 \% \mathrm{Cl} 0.82$ to $1.26, \mathrm{p}=0.87$ ). The incidence of nausea, jaw osteonecrosis and fatigue was similar for the two drugs, but the incidence of adverse renal events was significantly lower in the ibandronate group.

Conclusions: Ibandronate significantly reduces the incidence of skeletal-related events and bone pain in patients with MBD or multiple myeloma relative to placebo. It is associated with a similar incidence of skeletal-related events as zoledronate.

\section{Strengths and limitations of this study}

- First meta-analysis on ibandronate for metastatic cancer or multiple myeloma.

- Compared the efficacy and adverse events of ibandronate and zoledronate directly.

- Limited by lacking subgroup analysis based on drug delivery route or treatment duration.

\section{INTRODUCTION}

Breast cancer, prostate cancer and particularly multiple myeloma frequently metastasise to the skeleton. Patients with bone metastases often suffer fractures and severe pain, which reduces their quality of life. Metastatic bone disease (MBD) often develops into skeletalrelated events, defined as hypercalcemia, pathological fracture, radiotherapy or surgery involving bone and spinal cord compression. ${ }^{12}$ Treatment options for SREs and bone pain include chemotherapy, hormone therapy, radiotherapy, radiopharmaceuticals, surgery, analgesics and bisphosphonates. Even though patients may achieve effective improvement with these treatments, some will continue to experience severe and refractory bone pain. ${ }^{34}$

Selection of the treatment method should be based on tumour size, location of metastases, patient's general health, symptoms and life expectancy; method selection should also take into account the possible side effects. Older patients often suffer from reduced renal function and other complicating medical conditions, which requires even more careful treatment selection. ${ }^{5}$

Bone metastases are classified as osteolytic, osteosclerotic or mixed lesions. ${ }^{6}{ }^{7}$ Osteolytic metastases are believed to be caused by 
osteoclast-activating factors, the most important of which may be parathyroid hormone-related peptide. Osteoblastic metastases, in contrast, are believed to arise when cancer cells produce factors that stimulate osteoblast proliferation, differentiation and bone formation. The relative activity of osteoclasts and osteoblasts maintains a balance that ensures bone strength and integrity. A balance between levels of osteoprotegerin and of the receptor activator of the nuclear factor- $\kappa \beta$ ligand (RANKL) is important in bone pathophysiology and it is a drug target in the treatment of bone metastases and osteoarthritis. Bisphosphonates or RANKL inhibitors such as denosumab are the current standard of care for treating SREs or bone pain in primary and metastatic bone cancers. ${ }^{8}$ These drugs strengthen the skeleton and may also make the bones less receptive to activation by neoplastic osteoclasts. Four bisphosphonates have been approved for clinical use: pamidronate, ibandronate, zoledronate and clodronate. These drugs are chemically and structurally different, which helps to explain their different clinical efficacies. ${ }^{9} 10$

Ibandronate, approved in 2003 by the European Union for treating patients with metastatic breast cancer, inhibits osteoclast activity and osteoclast-mediated bone resorption, leading to osteoclast apoptosis. Pharmacokinetic data demonstrate that a 30 -min fasting period results in a bioavailability of $0.44 \%$ for a $50 \mathrm{mg}$ daily oral dose, and it provides comparable bone-surface exposure to intravenous ibandronate $(6 \mathrm{mg})$ infused every 3 to 4 weeks ie, the two formulations are dose-equivalent. ${ }^{11}$ However, clinical trials on ibandronate to treat patients with bone metastases arising from breast cancer, colorectal cancer and multiple myeloma have given conflicting results about efficacy and safety. ${ }^{12-14}$

Zoledronate is also widely used to treat MBD. Our previous study indicated that intravenous zoledronate $(4 \mathrm{mg})$ offers good clinical benefit to patients with MBD. ${ }^{15}$ Ibandronate and zoledronate are generally well tolerated, triggering primarily transient side effects such as mild flu-like symptoms. However, all bisphosphonates have a potential for side effects such as jaw osteonecrosis and renal toxicity. Bisphosphonate-induced jaw osteonecrosis can cause mutilation, impairment of function and esthetics in the orofacial system. It is supposed that awareness and good knowledge of this disease among physicians are important factors for its early detection and management. As to renal adverse events, several trials have reported that zoledronate can cause lifethreatening renal toxicity. ${ }^{16-18}$

Ibandronate is associated with lower nephrotoxicity than zoledronate $^{19}$ and can be administered orally, which can be more cost-effective than an intravenous approach and which makes the therapy well suited to patients who have a phobia of needles. Self-administered oral ibandronate therapy is also convenient for patients who would otherwise require administration in hospital or during a home nursing visit. Whether one drug or the other is superior in the clinic, however, is poorly understood, since few studies have compared them for their safety and efficacy in treating SREs and bone pain.

To address these questions, we conducted a systematic review and meta-analysis evaluating the efficacy and safety of ibandronate relative to placebo or zoledronate for treating SREs and bone pain in MBD and multiple myeloma.

\section{PATIENTS AND METHODS}

\section{Study identification}

Literature searches were carried out to identify all relevant randomised controlled trials (RCTs) comparing ibandronate with placebo or zoledronate for treating patients with MBD or multiple myeloma. The searches were performed by two authors (C-JG and J-HZ). PubMed, EMBASE and the Cochrane Library databases were systematically searched for relevant articles published up to March 2015. The following search terms were used: (ibandronate OR zoledronate) AND (bone metastasis OR metastatic bone disease OR bone pain). Detailed database search strategies are shown in table 1 . We also manually searched reference lists in each article to identify additional studies. Moreover, abstracts of official conferences and other previously unpublished data were searched.

\section{Study selection}

Studies were included if they (1) involved patients at least 18 years of age with any type of MBD or multiple myeloma who had bone metastasis in at least one site; (2) assessed the clinical effects of ibandronate and reported at least one type of SRE, bone pain or adverse event and (3) included a placebo-control arm or a zoledronate as an 'active control' arm. Studies were included regardless of the dosage, delivery route (intravenous or oral) or duration of ibandronate or zoledronate therapy.

\section{Quality assessment}

The Jadad scale was used to assess the quality of the RCTs we selected. It is a five-point scale, with trials scoring 1 or 2 points considered low quality and 3-5 points considered high quality. ${ }^{5}$ We assessed whether (1) the trial was randomised, (2) the authors provided a sufficiently detailed description of the randomisation method, (3) the trial was double blind, (4) the blinding method was described in sufficient detail and (5) withdrawals were reported.

\section{Outcome measures}

Primary outcomes were the incidence of SREs and mean change in bone pain scores from baseline. Secondary outcomes were the incidence of adverse events such as abdominal pain, diarrhoea, nausea, fever or influenzalike symptoms, renal toxicity and jaw osteonecrosis.

\section{Data extraction}

We used a standardised form to extract and combine data from all eligible studies that reported the number 
Table 1 Database search strategies

\begin{tabular}{|c|c|c|}
\hline Database & $\begin{array}{l}\text { Time span of } \\
\text { search }\end{array}$ & Search strategy \\
\hline EMBASE (Ovid SP) & $\begin{array}{l}1990 \text { to March } \\
2015\end{array}$ & 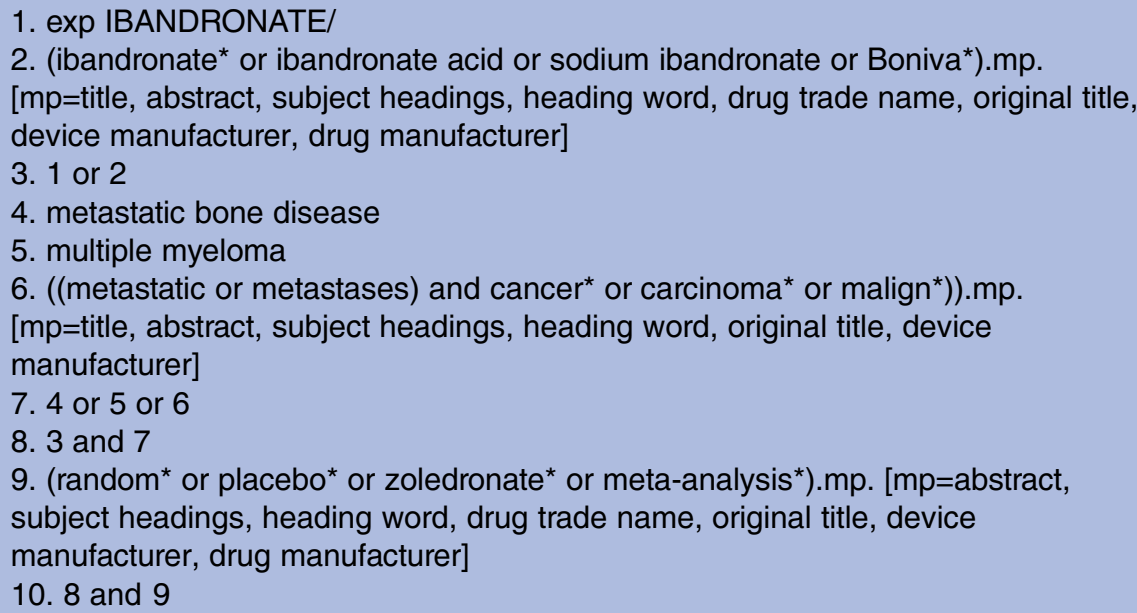 \\
\hline MEDLINE (Ovid SP) & $\begin{array}{l}1980 \text { to March } \\
2015\end{array}$ & $\begin{array}{l}\text { 1. exp Ibandronate/ } \\
\text { 2. (ibandronate* or ibandronate acid or sodium ibandronate or Boniva*).mp. } \\
\text { [mp=title, original title, abstract, name of substance word, subject heading word, } \\
\text { unique identifier] } \\
\text { 3. } 1 \text { or } 2 \\
\text { 4. metastatic bone disease } \\
\text { 5. multiple myeloma } \\
\text { 6. ((metastatic or metastases) and cancer* or carcinoma* or malign*)).mp. } \\
\text { [mp=title, original title, abstract, name of substance word, subject heading word, } \\
\text { unique identifier] } \\
\text { 7. } 4 \text { or } 5 \text { or } 6 \\
\text { 8. } 3 \text { and } 7\end{array}$ \\
\hline Cochrane Central & Inception to & \#1 MeSH descriptor ibandronate explode all trees \\
\hline $\begin{array}{l}\text { Register of Controlled } \\
\text { Trials (CENTRAL) in } \\
\text { The Cochrane Library }\end{array}$ & 2015 & $\begin{array}{l}\text { \#2 (ibandronate }{ }^{\star} \text { or ibandronate acid or sodium ibandronate or Boniva*) } \\
\text { \#3 \#1 OR \#2 } \\
\text { \#4 MeSH descriptor metastatic bone disease, multiple myloma explode all trees } \\
\text { \#5 MeSH descriptor metastatic cancer, bone metastasis, bone pain explode all } \\
\text { trees } \\
\left.\text { \#6 ((metastatic or metas tases) and cancer }{ }^{\star} \text { or carcinoma* or malign }{ }^{\star}\right) \text { ) } \\
\text { \#7 \#4 OR \#5 OR \#6 } \\
\text { \#8 \#3 AND \#7 }\end{array}$ \\
\hline
\end{tabular}

of patients with any type of SRE, the mean change in bone pain score from baseline and adverse events. Data were extracted independently by two authors (C-JG and QL) and discrepancies were resolved by discussion with a third reviewer (F-YM).

Intention-to-treat (ITT) analysis was used wherever possible. The ITT population was defined as participants who underwent randomisation, took the assigned study medication and provided at least one post-baseline assessment. When the ITT population was not available, we planned to use a safety set population instead. The safety set population referred to participants who received at least one study medication. When data could not be pooled directly for meta-analysis, we transformed them using formulas recommended by the Cochrane Handbook for Systematic Reviews of Interventions. ${ }^{20}$

\section{Statistical analysis}

RevMan 5.1 (Cochrane Collaboration) was used to meta-analyse the data. For dichotomous data, such as the incidence of SREs and adverse events, risk ratios (RRs) with $95 \%$ CIs were calculated. For continuous data, such as mean change in bone pain score from baseline, the weighted mean difference (WMD) was calculated as long as outcomes were measured in the same way between trials. The $\chi^{2}$ test was used to analyse the heterogeneity of trial results and the $\mathrm{I}^{2}$ test to assess inconsistency among trials. Heterogeneity was defined as significant if $\mathrm{p}<0.1$ for the $\chi^{2}$ test. Pooled estimates were calculated using a fixed effects model if substantial heterogeneity was not observed; otherwise, the estimate was calculated using a random-effects model. Unless otherwise noted, $\mathrm{p}<0.05$ served as the threshold for statistical 
significance. Outcomes that could not be meta-analysed were presented descriptively.

\section{Sensitivity analysis}

We checked the reliability of our meta-analyses by comparing the outcomes obtained from a random-effects model and from a fixed effects model. Robust pooled estimates should not depend on the choice of model.

\section{RESULTS}

\section{Identification and characteristics of studies}

Ten RCTs ${ }^{12-14} 21-27$ containing 3474 patients met the inclusion criteria and were included in this meta-analysis (figure 1). Six studies ${ }^{12-14}$ 21-23 were placebo-controlled, and the remaining four compared ibandronate with zoledronate. ${ }^{24-27}$ Most studies were carried out in Greece, Russia, Kuwait, South Africa, Germany, the UK and the USA, and most patients were Caucasian. One study $^{25}$ was carried out in India with Asian participants. Three studies ${ }^{12} 2126$ involved only female patients, six studies $^{1422-25} 27$ involved both sexes and one study ${ }^{13}$ did not report the sex of the participants. Seven studies $^{12} 1321222627$ evaluated breast cancer involving bone metastases, two articles ${ }^{23} 25$ studied several types of carcinoma including multiple myeloma, one study ${ }^{24}$ evaluated non-small cell lung cancer, and one study ${ }^{14}$ evaluated multiple myeloma. Four studies ${ }^{12} \quad 24 \quad 26 \quad 27$ involved a therapy regimen of oral ibandronate $(50 \mathrm{mg})$ once daily; one study, ${ }^{23}$ different doses of an oral formulation $(5,10,20,50 \mathrm{mg})$; three studies, ${ }^{13} 22{ }^{25}$ ibandronate $(6 \mathrm{mg})$ delivered intravenously every $3-4$ weeks; one study, ${ }^{14}$ ibandronate $(2 \mathrm{mg})$ delivered intravenously every 4 weeks; and one study, ${ }^{21}$ ibandronate (2 or $6 \mathrm{mg}$ ) delivered intravenously every 4 weeks. Other details of included studies are shown in table 2.

\section{Quality assessment of the studies}

The mean Jadad score was 3.5 for the six placebocontrolled studies in the meta-analysis, and 2.5 for the four studies comparing ibandronate and zoledronate (table 2). The lower score for the two-drug studies was because all were open label. All ten studies mentioned randomisation, but only four described the randomisation method. ${ }^{12} 14 \quad 2627$ Five of six placebo-controlled trials $^{12} 1^{14}{ }^{21-23}$ stated that they were double blind, but only two reported the blinding method in detail. ${ }^{12}{ }^{21}$ All ten studies reported the number of withdrawals.

\section{Therapy outcomes}

We did not perform subgroup analyses based on the drug delivery route, treatment duration, ethnicity or sex, because of the lack of studies reporting such comparisons. In the end, we performed subgroup analysis only for drug dose: intravenous ibandronate $(2 \mathrm{mg})$ versus intravenous ibandronate $(6 \mathrm{mg})$ or oral ibandronate $(50 \mathrm{mg})$. This subgroup analysis was performed for the
Figure 1 Selection of trials included in this meta-analysis.

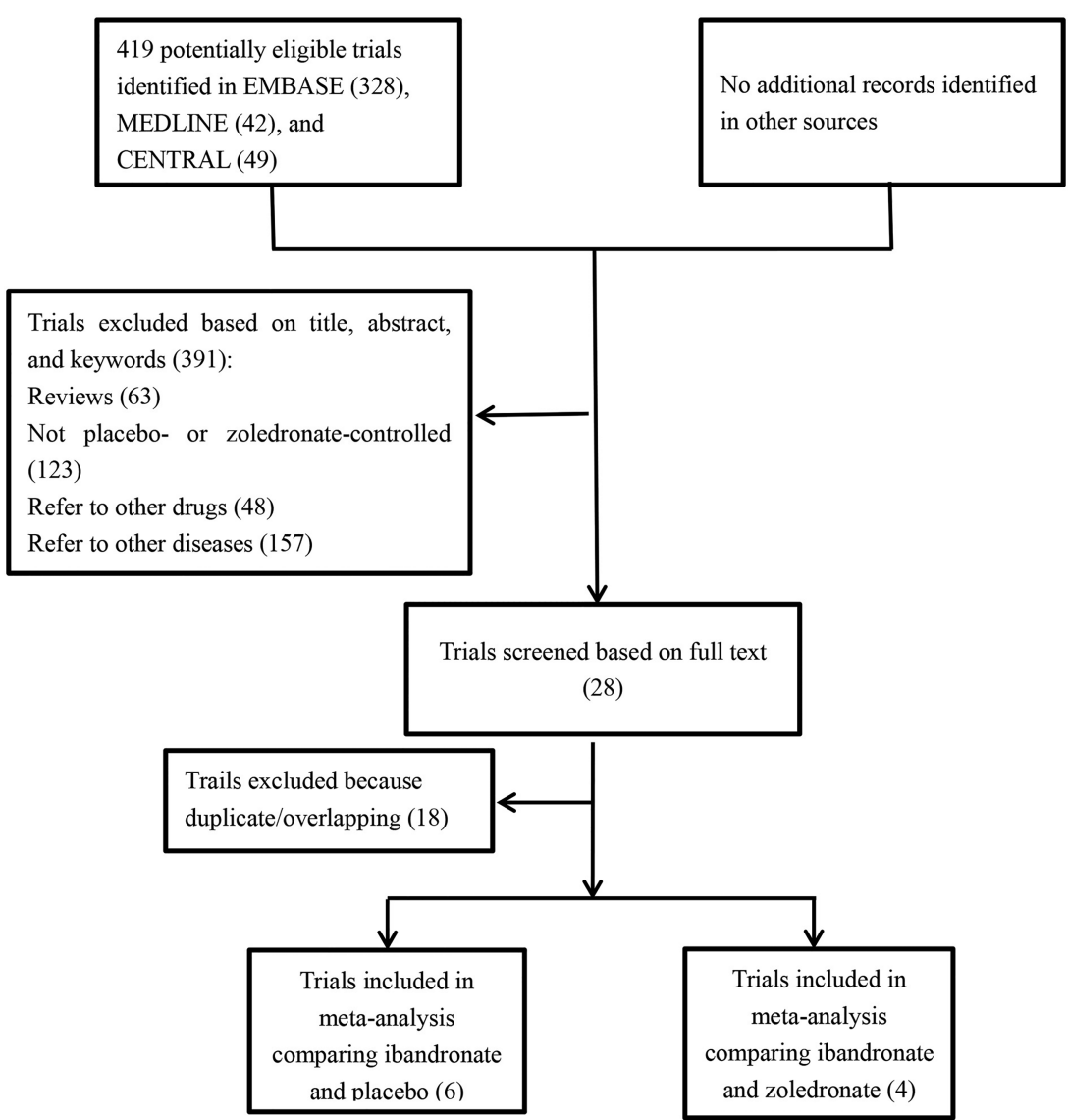


Table 2 Characteristics of included studies comparing ibandronate with placebo or zoledronate for treating patients with metastatic bone disease or multiple myeloma

\begin{tabular}{|c|c|c|c|c|c|c|c|c|}
\hline Study & Arm & $\mathbf{N}$ & Dose and route & Treatment duration & $\begin{array}{l}\text { Change in bone pain } \\
\text { score from baseline }\end{array}$ & Gender (M/F) & Jadad score & ITT \\
\hline Body et al ${ }^{2}$ & $\begin{array}{l}\text { Ibandronate } \\
\text { Placebo }\end{array}$ & $\begin{array}{l}287 \\
277\end{array}$ & Oral $50 \mathrm{mg}$ daily & 96 weeks & $\begin{array}{l}-0.1 \pm 1.89 \\
+0.2 \pm 1.10\end{array}$ & $0 / 564$ & 5 & $\overline{\text { Yes }}$ \\
\hline Diel et a ${ }^{21}$ & $\begin{array}{l}\text { Ibandronate } \\
\text { Ibandronate } \\
\text { Placebo }\end{array}$ & $\begin{array}{l}154 \\
154 \\
158\end{array}$ & $\begin{array}{l}\text { Intravenously } 6 \mathrm{mg} \text { every } 3-4 \text { weeks } \\
\text { Intravenously } 2 \mathrm{mg} \text { every } 3-4 \text { weeks }\end{array}$ & 60-96 weeks & $\begin{array}{l}+0.21 \pm 0.09 \\
-0.28 \pm 1.11 \\
+0.19 \pm 0.11\end{array}$ & $0 / 466$ & 4 & Yes \\
\hline Heras et $a l^{13}$ & $\begin{array}{l}\text { Ibandronate } \\
\text { Placebo }\end{array}$ & $\begin{array}{l}37 \\
36\end{array}$ & Intravenously 6 mg every 4 weeks & 9 months & - & - & 2 & Yes \\
\hline Menssen et $a l^{14}$ & $\begin{array}{l}\text { Ibandronate } \\
\text { Placebo }\end{array}$ & $\begin{array}{l}99 \\
99\end{array}$ & Intravenously $2 \mathrm{mg}$ every 4 weeks & 12-24 months & - & $104 / 94$ & 4 & Yes \\
\hline Heras et $a R^{2}$ & $\begin{array}{l}\text { Ibandronate } \\
\text { Placebo }\end{array}$ & $\begin{array}{l}75 \\
75\end{array}$ & Intravenously $6 \mathrm{mg}$ every 4 weeks & 24 months & - & $2 / 148$ & 3 & Yes \\
\hline Coleman et $a^{P^{3}}$ & $\begin{array}{l}\text { Ibandronate } \\
\text { Ibandronate } \\
\text { lbandronate } \\
\text { lbandronate } \\
\text { Placebo }\end{array}$ & $\begin{array}{l}21 \\
23 \\
22 \\
22 \\
20\end{array}$ & $\begin{array}{l}\text { Oral } 5 \mathrm{mg} \text { daily } \\
\text { Oral } 10 \mathrm{mg} \text { daily } \\
\text { Oral } 20 \mathrm{mg} \text { daily } \\
\text { Oral } 50 \mathrm{mg} \text { daily }\end{array}$ & 4 weeks & - & $26 / 84$ & 3 & Yes \\
\hline Francini et $a P^{4}$ & $\begin{array}{l}\text { Ibandronate } \\
\text { Zoledronate }\end{array}$ & $\begin{array}{l}27 \\
26\end{array}$ & $\begin{array}{l}\text { Oral } 50 \mathrm{mg} \text { daily } \\
\text { Intravenously } 4 \mathrm{mg} \text { every } 4 \text { weeks }\end{array}$ & 6 months & - & $41 / 14$ & 2 & - \\
\hline Choudhury et $a^{25}$ & $\begin{array}{l}\text { Ibandronate } \\
\text { Zoledronate } \\
\text { Pamidronate }\end{array}$ & $\begin{array}{l}65 \\
60 \\
62\end{array}$ & $\begin{array}{l}\text { Intravenously } 6 \mathrm{mg} \text { every } 3-4 \text { weeks } \\
\text { Intravenously } 4 \mathrm{mg} \text { every } 3-4 \text { weeks } \\
\text { Intravenously } 90 \text { mg every } 3-4 \text { weeks }\end{array}$ & - & $\begin{array}{l}-3.9 \pm 0.41 \\
-4.4 \pm 0.36\end{array}$ & $154 / 33$ & 2 & Yes \\
\hline Body et $a P^{R 6}$ & $\begin{array}{l}\text { Ibandronate } \\
\text { Zoledronate }\end{array}$ & $\begin{array}{r}0< \\
137 \\
137\end{array}$ & $\begin{array}{l}\text { Oral } 50 \mathrm{mg} \text { daily } \\
\text { Intravenously } 4 \mathrm{mg} \text { every } 4 \text { weeks }\end{array}$ & 12 weeks & $\begin{array}{l}-0.24 \pm 0.77 \\
-0.18 \pm 0.78\end{array}$ & 0/274 & 3 & Yes \\
\hline Barrett-Lee et $a^{P^{7}}$ & $\begin{array}{l}\text { Ibandronate } \\
\text { Zoledronate }\end{array}$ & $\begin{array}{l}704 \\
697\end{array}$ & $\begin{array}{l}\text { Oral } 50 \mathrm{mg} \text { daily } \\
\text { Intravenously } 4 \text { mg every } 4 \text { weeks }\end{array}$ & 96 weeks & - & $18 / 1382^{*}$ & 3 & Yes \\
\hline
\end{tabular}




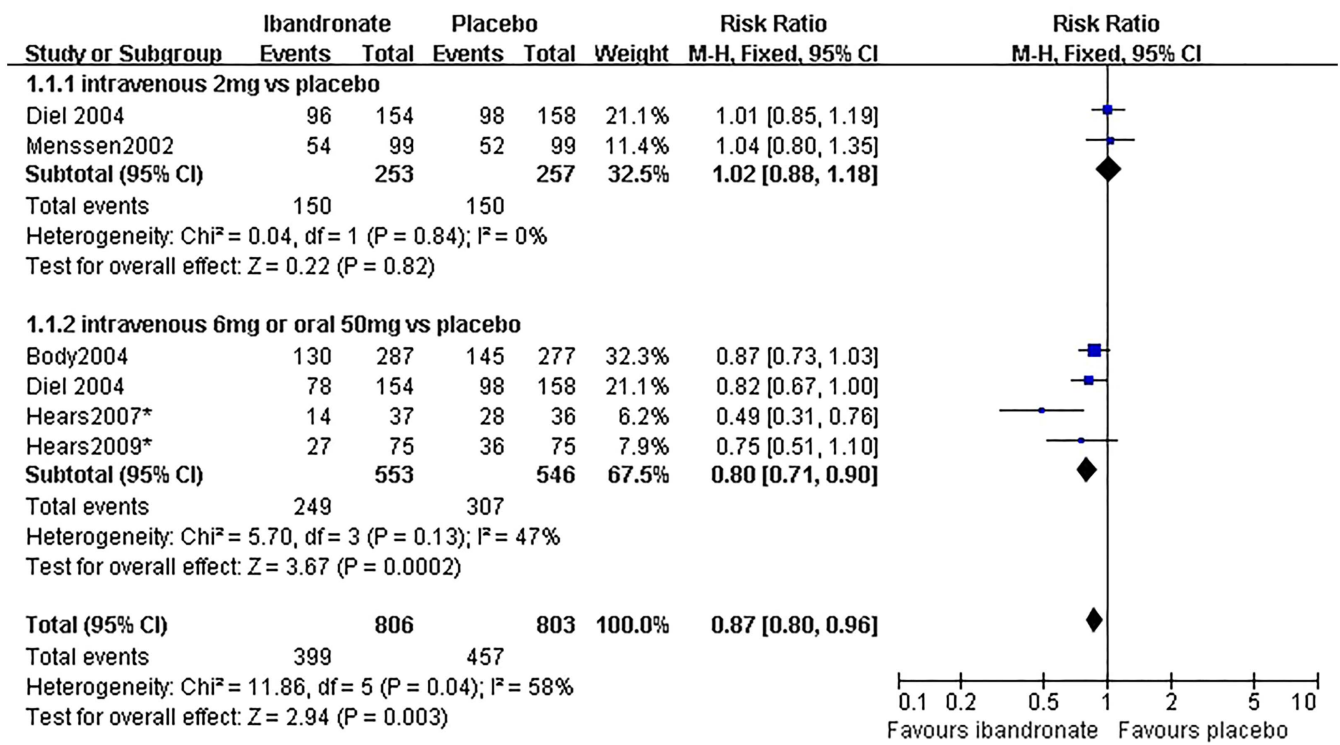

Figure 2 Comparison of the effects of ibandronate and placebo for reducing all skeletal-related events.

primary outcomes of incidence of SREs and mean change in bone pain score from baseline.

\section{Incidence of SRES}

Five of six placebo-controlled trials ${ }^{12-14} 2122$ reported data on the incidence of SREs. Both effect models indicated a significantly lower incidence with ibandronate than with placebo (RR $0.87,95 \%$ CI 0.80 to 0.96 , $\mathrm{p}=0.003$, fixed effects; $\mathrm{I}^{2}=58 \%$ ). Subgroup analysis showed no significant differences between intravenous ibandronate (2 mg) and placebo ( $R R$ 1.02, $\mathrm{p}=0.82$ ), while intravenous ibandronate $(6 \mathrm{mg})$ every $3-4$ weeks or daily oral ibandronate $(50 \mathrm{mg})$ was associated with significantly lower incidence than was placebo (RR 0.80 , $\mathrm{p}=0.002$; figure 2). We made a funnel plot of ibandronate and placebo for reducing all SRE (figure 3).
Two of four trials ${ }^{24} 27$ comparing ibandronate with zoledronate reported data on the incidence of SREs. The two drugs were associated with similar incidence (RR 1.02, 95\% CI 0.82 to $1.26, p=0.87$ ), and this meta-analysis did not show significant heterogeneity $\left(\mathrm{I}^{2}=37 \%\right.$; figure 4$)$.

\section{Mean change in bone pain score from baseline}

Two placebo-controlled studies ${ }^{12}{ }^{21}$ reported data on the mean change in bone pain score from baseline (table 2). Bone pain used the patient-rated scoring system. Patients were asked to rate how severe their bone pain had been, on average, over the previous week using a scale of 0 (none), 1 (mild), 2 (moderate), 3 (severe) or 4 (intolerable). Initial meta-analysis indicated that placebo was associated with a significantly greater reduction in bone pain score from baseline than was ibandronate at
Figure 3 Funnel plot of ibandronate and placebo for reducing all skeletal-related events.

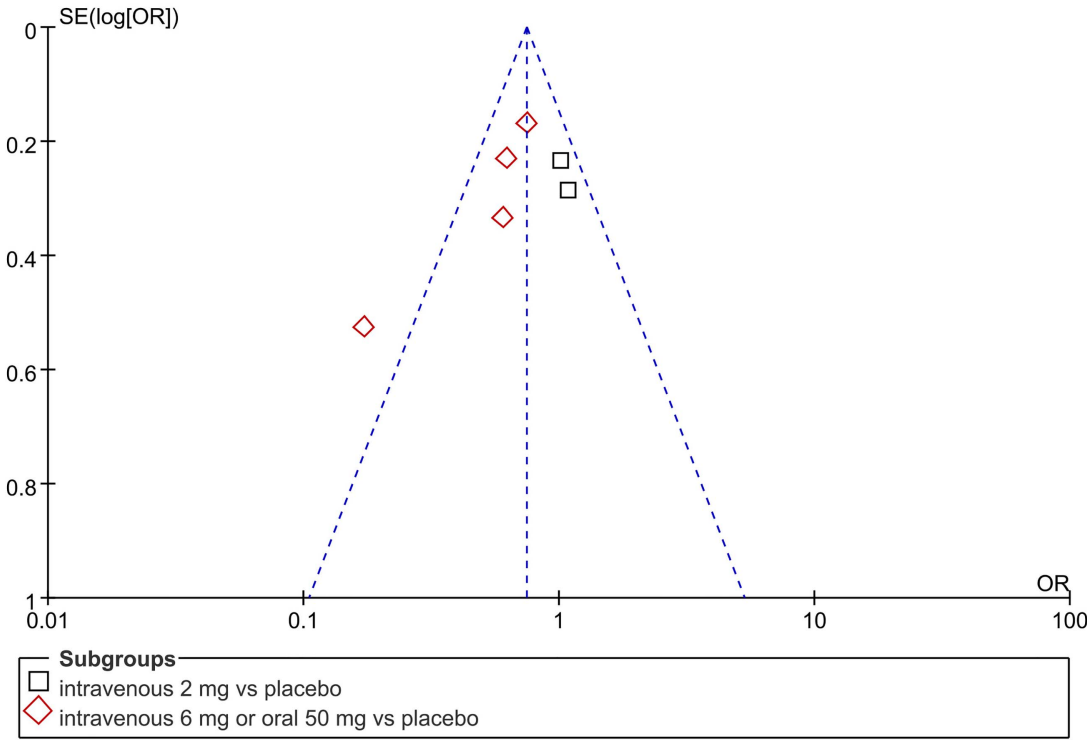




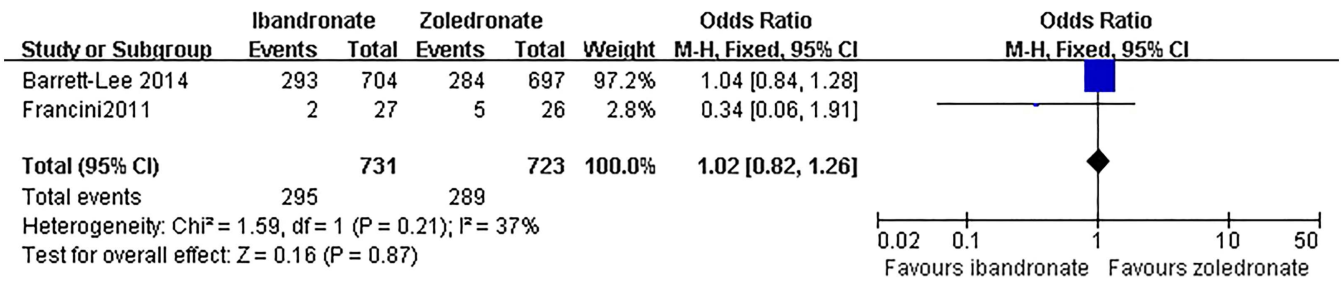

Figure 4 Comparison of the effects of ibandronate and zoledronate for reducing all skeletal-related events.

96 weeks (WMD $=0.05,95 \%$ CI 0.03 to $0.07, \mathrm{p}<0.001$, fixed effects), but the pooled estimate showed significant heterogeneity $\left(I^{2}=87 \%\right)$. Therefore, we performed a subgroup meta-analysis in which we eliminated data for patients who received intravenous ibandronate $(2 \mathrm{mg})$. The resulting meta-analysis showed that intravenous ibandronate $(6 \mathrm{mg})$ every $3-4$ weeks or daily oral ibandronate $(50 \mathrm{mg})$ was associated with a significantly greater reduction in bone pain score from baseline than was placebo at 96 weeks (WMD $=-0.41,95 \%$ CI -0.56 to $-0.27, \mathrm{p}<0.001$, fixed effects model; heterogeneity: $\mathrm{I}^{2}=14 \%$; figure 5).

One placebo-controlled study ${ }^{14}$ described that ibandronate significantly decreased bone pain scores compared with placebo (Wilcoxon rank sum test; $\mathrm{p}<0.047$ ), but without data in detail. Another three studies ${ }^{13} 2223$ did not report data on bone pain.

Two studies ${ }^{25}{ }^{26}$ comparing ibandronate and zoledronate reported data on the mean change in bone pain score from baseline. We were unable to pool the data on this outcome because bone pain was not measured in comparable ways. Two trials ${ }^{24} 27$ reporting the effect of ibandronate and zoledronate on pain relief were presented descriptively. These four studies compared bone pain relief using different pain scoring systems: the McGill pain questionnaire, ${ }^{24}$ the brief pain inventory ${ }^{25} 27$ and the patient-rating scoring system. ${ }^{26}$ Three RCTs 242627 showed no significant difference between the two drugs in reducing bone pain. One RCT ${ }^{25}$ involving 65 patients in the ibandronate group and 60 in the zoledronate group found that zoledronate was superior to ibandronate at 6 months with a $p$ value of 0.024 . However, the two drugs showed no significant difference at 3 months or at the end of the study.

\section{Adverse events}

Adverse events were analysed in placebo-controlled trials without adjusting for median duration of therapy (table 3). Incidence of abdominal pain was significantly higher in the ibandronate group $(7.0 \%)$ than in the placebo group $(1.5 \%)$ based on fixed effects meta-analysis (RR 2.26, 95\% CI 1.09 to $4.70, \mathrm{p}=0.03 ; \mathrm{I}^{2}=7 \%$ ), although random-effects analysis indicated no significant difference $(p=0.11)$. Meta-analysis using fixed effects or random-effects models showed similar incidence between the two groups for the following adverse events (only fixed effects meta-analysis shown): diarrhoea, $6 \%$ in the drug group versus $0.8 \%$ in the placebo group, RR 3.72, 95\% CI 0.96 to 14.38 , $p=0.06$; nausea, $6.4 \%$ versus $2.0 \%$, RR $2.05,95 \%$ CI 0.85 to 4.95 , $\mathrm{p}=0.11$; and renal toxicity, $3.4 \%$ versus $3.4 \%$, RR $1.14,95 \%$ CI 0.59 to $2.21, \mathrm{p}=0.69$. No significant heterogeneity was detected among the trials $\left(\mathrm{I}^{2}<50 \%\right)$.

Adverse events were also analysed in trials comparing ibandronate and zoledronate without adjusting for median duration of therapy (table 4). Incidence of renal toxicity was lower in the ibandronate group (23.7\%) than the zoledronate group $(31.8 \%)$ based on fixed effects meta-analysis (RR $0.74,95 \%$ CI 0.63 to 0.88 , $\mathrm{p}=0.006 ; \mathrm{I}^{2}=9 \%$ ), although random-effects meta-analysis indicated no significant difference $(p=0.18)$. Similar results were obtained for the incidence of fever or influenza-like symptoms ( $19.6 \%$ vs $36.3 \%)$, which was significantly lower for ibandronate based on fixed effects meta-analysis (RR $0.54,95 \%$ CI 0.46 to $0.63, \mathrm{p}<0.001$; heterogeneity: $\mathrm{I}^{2}=80 \%$ ) and slightly lower for ibandronate based on random-effects meta-analysis $(p=0.05)$. Meta-analysis using fixed effects or random-effects models showed a similar incidence between the two groups for the following adverse events (only fixed effects meta-analysis shown): anorexia, $35.6 \%$ in the ibandronate group versus $36.3 \%$ in the zoledronate group, RR $0.98,95 \%$ CI 0.86 to $1.12, \mathrm{p}=0.77$; nausea, $57.3 \%$ versus $58.1 \%$, RR 0.99 , $95 \%$ CI 0.91 to 1.08 , $\mathrm{p}=0.78$; fatigue, $74.5 \%$ versus $76 \%$, RR $0.98,95 \%$ CI 0.93 to $1.04, \mathrm{p}=0.56$; and jaw osteonecrosis, $0.7 \%$ versus $1.4 \%$, RR $0.52,95 \%$ CI 0.19 to $1.44, \mathrm{p}=0.21$. No significant heterogeneity was detected among the trials $\left(\mathrm{I}^{2}<50 \%\right)$.

\begin{tabular}{|c|c|c|c|c|c|c|c|c|c|}
\hline \multirow[b]{2}{*}{ Stucty or Subgroup } & \multicolumn{3}{|c|}{ Ibandronate } & \multicolumn{2}{|c|}{ Placebo } & \multirow[b]{2}{*}{ Total } & \multirow[b]{2}{*}{ Weight } & \multirow{2}{*}{$\begin{array}{l}\text { Mean Difference } \\
\text { N, Fixed, 95\% Cl }\end{array}$} & \multirow{2}{*}{$\begin{array}{l}\text { Mean Difference } \\
\text { N, Fixed, 95\% Cl }\end{array}$} \\
\hline & Mean & SD & Total & Mean & SD & & & & \\
\hline Body2004 & -0.1 & 1.89 & 287 & 0.2 & 1.1 & 277 & $32.4 \%$ & $-0.30[-0.55,-0.05]$ & \\
\hline Diel 2004 & -0.28 & 1.11 & 154 & 0.19 & 0.11 & 158 & $67.6 \%$ & $-0.47[-0.65,-0.29]$ & \\
\hline Total $(95 \% \mathrm{Cl})$ & & & 441 & & & 435 & $100.0 \%$ & $-0.41[-0.56,-0.27]$ & \\
\hline $\begin{array}{l}\text { Heterogeneity: } \mathrm{Chi}^{2}= \\
\text { Test for overall effect }\end{array}$ & $\begin{array}{l}1.16, \mathrm{df} \\
Z=5.62\end{array}$ & $\begin{array}{l}=1(P \\
(P<0\end{array}$ & $\begin{array}{l}=0.28) \\
.00001\end{array}$ & $; F^{2}=1$ & & & & & 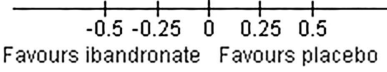 \\
\hline
\end{tabular}

Figure 5 Comparison of the mean change in bone pain score from baseline at 96 weeks of treatment with ibandronate or placebo (iv, intravenous). 
Table 3 Comparison of adverse events in patients on ibandronate or placebo therapy

\begin{tabular}{|c|c|c|c|c|c|c|}
\hline \multirow[b]{2}{*}{ Adverse event } & \multirow{2}{*}{$\begin{array}{l}\text { Studies } \\
\text { reporting, } \mathbf{n}\end{array}$} & \multicolumn{2}{|c|}{$\begin{array}{l}\text { Patients reporting/total } \\
\text { number }\end{array}$} & \multirow[b]{2}{*}{ RR $(95 \% \mathrm{Cl})$} & \multirow[b]{2}{*}{ p Value } & \multirow{2}{*}{$\begin{array}{l}\text { p For } \\
\text { heterogeneity }\end{array}$} \\
\hline & & Ibandronate & Placebo & & & \\
\hline Abdominal pain & 4 & $34 / 487$ & $6 / 408$ & 2.26 (1.09 to 4.70$)$ & 0.03 & 0.36 \\
\hline Diarrhoea & 3 & $12 / 200$ & $1 / 131$ & $3.72(0.96$ to 14.38$)$ & 0.06 & 0.40 \\
\hline Nausea & 2 & $24 / 375$ & $6 / 297$ & 2.05 (0.85 to 4.95$)$ & 0.11 & 0.65 \\
\hline Renal toxicity & 2 & $20 / 595$ & $15 / 435$ & 1.14 (0.59 to 2.21$)$ & 0.69 & 0.88 \\
\hline
\end{tabular}

[Bold] means $p$ value served as the threshold for statistical significance. $R R$, risk ratio.

\section{DISCUSSION}

This meta-analysis suggests that intravenous ibandronate (6 mg) every 3-4 weeks or daily oral medication (50 mg) is more effective than placebo for patients with MBD or multiple myeloma. In addition, ibandronate is well tolerated for at least 96 weeks, with a similar risk of diarrhoea, nausea and renal toxicity for drug and placebo. However, ibandronate is associated with a significantly higher risk of abdominal pain compared with placebo. Our meta-analysis also suggests that ibandronate and zoledronate reduce the incidence of SREs to a similar extent and are associated with similar risk of anorexia, nausea, fatigue and jaw osteonecrosis. Ibandronate was associated with a significantly lower incidence of renal toxicity than zoledronate and with a slightly lower incidence of fever or influenza-like symptoms than zoledronate.

The quality of the six placebo-controlled studies in our review was high (Jadad score $\geq 3$ ), with only one study ${ }^{13}$ earning two points because it failed to report the randomisation method in detail and it did not clearly indicate whether it was double blinded or not. The quality of the four trials comparing ibandronate and zoledronate was lower because the studies were open label. All ten studies used a parallel design for the ibandronate and placebo or zoledronate arms.

Sensitivity analysis, which we performed by comparing the RRs using fixed effects or random-effects models, showed that most pooled risk estimates were robust except for the meta-analysis of the incidence of abdominal pain between the ibandronate and placebo groups, as well as the incidence of renal toxicity between the ibandronate and zoledronate groups. In two cases, the random-effects model showed no significant difference between the two groups, while the fixed effects model showed a significantly lower incidence of abdominal pain in the placebo group, and a significantly lower incidence of renal toxicity in the ibandronate group.

We identified five meta-analyses evaluating bisphosphonates in patients with breast cancer, ${ }^{28}$ prostate cancer, ${ }^{29}$ lung cancer, ${ }^{30}$ multiple myeloma ${ }^{31}$ or various cancers. $^{32}$ These analyses all focused on SREs and few examined the therapeutic effects on bone pain. They also pooled data for different bisphosphonates, even though different members of this synthetic drug family vary in clinical activity and potency; thus, findings from those meta-analyses should be treated with caution. Our meta-analysis focused specifically on ibandronate, commonly used to prevent SREs in patients with cancer with MBD or multiple myeloma. Our meta-analysis shows that ibandronate is more effective than placebo at preventing SREs in the long term, suggesting that prolonged clinical use of this drug is justified. Our meta-analysis also suggests that ibandronate and zoledronate show equivalent ability to prevent SREs. This gives clinicians another option if either drug is deemed unsuitable for a patient.

Our meta-analysis of adverse events suggests that ibandronate is well tolerated for at least 96 weeks of treatment, and that the incidence of nausea and renal toxicity with this drug is similar to that with placebo. Ibandronate and zoledronate are associated with similar rates of fatigue, nausea and jaw osteonecrosis. In addition, ibandronate is associated with a significantly lower risk of adverse renal events than zoledronate and with a

Table 4 Comparison of adverse events in patients on ibandronate or zoledronate therapy

\begin{tabular}{|c|c|c|c|c|c|c|}
\hline \multirow[b]{2}{*}{ Adverse event } & \multirow{2}{*}{$\begin{array}{l}\text { Studies } \\
\text { reporting, } \mathbf{n}\end{array}$} & \multicolumn{2}{|c|}{$\begin{array}{l}\text { Patients reporting/total } \\
\text { number }\end{array}$} & \multirow[b]{2}{*}{ RR (95\% Cl) } & \multirow[b]{2}{*}{ p Value } & \multirow{2}{*}{$\begin{array}{l}\text { p For } \\
\text { heterogeneity }\end{array}$} \\
\hline & & Ibandronate & Zoledronate & & & \\
\hline Anorexia & 2 & $274 / 769$ & $275 / 757$ & 0.98 (0.86 to 1.12$)$ & 0.77 & 0.29 \\
\hline Fatigue & 2 & $573 / 769$ & $575 / 757$ & 0.98 (0.93 to 1.04$)$ & 0.56 & 0.41 \\
\hline Fever or influenza-like symptoms & 4 & $183 / 933$ & $334 / 920$ & $0.47(0.22$ to 1.01$)$ & 0.05 & 0.002 \\
\hline Jaw osteonecrosis & 2 & $5 / 731$ & $10 / 723$ & $0.52(0.19$ to 1.44$)$ & 0.21 & 0.75 \\
\hline Renal toxicity & 2 & $173 / 731$ & 230/723 & $0.74(0.63$ to 0.88$)$ & $<0.001$ & 0.29 \\
\hline
\end{tabular}

[Bold] means $p$ value served as the threshold for statistical significance.

$\mathrm{RR}$, risk ratio. 
slightly lower risk of fever or influenza-like symptoms than zoledronate. In fact, one study examined a 4-year oral ibandronate therapy and reported no adverse renal effects, with serum creatinine levels remaining stable. ${ }^{33}$ Similar results were reported for intravenous ibandronate therapy lasting 4 years, ${ }^{19}$ suggesting that this class of bisphosphonates does not cause significant renal toxicity. However, a recent prospective, randomised, monocentric trial ${ }^{34}$ showed no significant difference in renal toxicity between intravenous ibandronate $(6 \mathrm{mg})$ and zoledronate $(4 \mathrm{mg})$. The observation period in that study was only 6 months, so it may have failed to detect toxicity differences in the longer term. In addition, the authors of that study excluded patients with risk factors for pre-existing kidney damage. Taken together, the available evidence suggests that when renal function is a concern, ibandronate may be safer than zoledronate. Nevertheless, serum creatinine levels should be monitored in patients on ibandronate therapy. The risk of jaw osteonecrosis with either drug suggests the need for caution, though no serious cases were reported for patients in our meta-analysis on either ibandronate or zoledronate therapy.

We did not perform subgroup analysis based on the ibandronate delivery route (oral vs intravenous) because of the lack of studies reporting this comparison. Nevertheless, we did prepare a table comparing the efficacy and side effects for the two delivery routes (table 5). This comparison suggests that there is a lower risk of SREs with an oral drug $(50 \mathrm{mg})$ than with an intravenous drug $(6 \mathrm{mg})$. Unfortunately, the use of different bone pain scoring systems prevented us from directly comparing the ability to reduce bone pain. Since oral $50 \mathrm{mg}$ dosing seems to increase the risk of abdominal pain, anorexia and fatigue, the selection of the delivery route should take into account efficacy and side effects.

One strength of our study is that it analyses a relatively large randomised cohort of patients treated with

\begin{tabular}{|c|c|c|}
\hline & \multicolumn{2}{|c|}{ Patients reporting/total no } \\
\hline & Oral 50 mg & $\begin{array}{l}\text { Intravenous } \\
6 \mathrm{mg}\end{array}$ \\
\hline \multicolumn{3}{|l|}{ Efficacy } \\
\hline SRES & $430 / 1018(42 \%)$ & $119 / 266(45 \%)$ \\
\hline \multicolumn{3}{|l|}{ Adverse event } \\
\hline Abdominal pain & $192 / 1013(19 \%)$ & $7 / 112(6 \%)$ \\
\hline Anorexia & $254 / 704(36 \%)$ & $28 / 65(43 \%)$ \\
\hline Diarrhoea & $210 / 726(30 \%)$ & $7 / 112(6 \%)$ \\
\hline Fatigue & $551 / 704(78 \%)$ & $30 / 65(46 \%)$ \\
\hline $\begin{array}{l}\text { Fever or influenza-like } \\
\text { symptoms }\end{array}$ & $279 / 704(36 \%)$ & $10 / 154(14 \%)$ \\
\hline Nausea & $428 / 1013(42 \%)$ & $32 / 65(49 \%)$ \\
\hline Renal toxicity & $245 / 1018(24 \%)$ & $5 / 154(3 \%)$ \\
\hline
\end{tabular}

ibandronate for metastatic cancer or multiple myeloma. To the best of our knowledge, it is also the first review that directly compares ibandronate and zoledronate in treating patients with metastatic cancer.

Despite these strengths, our meta-analysis does have limitations. First, three of the included studies ${ }^{13} 2425$ have low Jadad scores. Second, two studies ${ }^{13} 22$ did not report the final number of patients allocated to the treatment and placebo groups, so we had to assume that the patients were evenly distributed. Third, the small number of included studies meant that we were unable to perform subgroup analysis based on patient demographics, drug delivery route, treatment duration, disease characteristics or ethnicity. Finally, publication bias may exist.

Our review suggests that ibandronate can significantly prevent SREs and reduce bone pain with good tolerability in patients with MBD or multiple myeloma. Further studies on ibandronate should examine its efficacy and safety in patients of different ethnicities and different types of cancer. The efficacy and safety of the drug administered orally or intravenously for different treatment durations should also be rigorously examined.

\section{Author affiliations}

${ }^{1}$ Department of Anesthesiology, Affiliated Tumor Hospital of Guangxi Medical University, Nanning, People's Republic of China

${ }^{2}$ Postgraduate School of Guangxi Medical University, Nanning, People's Republic of China

${ }^{3}$ Hepatobiliary Surgery Department, Affiliated Tumor Hospital of Guangxi Medical University, Nanning, People's Republic of China

${ }^{4}$ Department of Anesthesiology, Affiliated Hospital of Chifeng University, Inner Mongolia Autonomous Region, Nanning, People's Republic of China ${ }^{5}$ Out-patient Department, Affiliated Tumor Hospital of Guangxi Medical University, Nanning, People's Republic of China

Acknowledgements The authors would like to thank A Chapin Rodríguez for his language editing and other suggestions, which helped improve the manuscript.

Contributors C-JG conceived and designed the experiments. C-JG, QL, J-HZ and F-YM performed the research. C-JG, NW, RL and B-YY performed the statistical analysis. C-JG and J-HZ wrote the manuscript. All authors have read and approved the final manuscript.

Funding This research received no specific grant from any funding agency in the public, commercial or not-for-profit sectors.

Competing interests None declared.

Patient consent Obtained.

Provenance and peer review Not commissioned; externally peer reviewed.

Data sharing statement No additional data are available.

Open Access This is an Open Access article distributed in accordance with the Creative Commons Attribution Non Commercial (CC BY-NC 4.0) license, which permits others to distribute, remix, adapt, build upon this work noncommercially, and license their derivative works on different terms, provided the original work is properly cited and the use is non-commercial. See: http:// creativecommons.org/licenses/by-nc/4.0/

\section{REFERENCES}

1. Coleman RE. Metastatic bone disease: clinical features, pathophysiology and treatment strategies. Cancer Treat Rev 2001;27:165-76. 
2. Coleman RE. Clinical features of metastatic bone disease and risk of skeletal morbidity. Clin Cancer Res 2006;12:6243s-9s.

3. Janjan N. Bone metastases: approaches to management. Semin Oncol 2001;28:28-34.

4. Serafini AN. Therapy of metastatic bone pain. J Nucl Med 2001;42:895-906.

5. Jadad AR, Moore RA, Carroll D, et al. Assessing the quality of reports of randomized clinical trials: is blinding necessary? Control Clin Trials 1996;17:1-12.

6. Roodman GD. Mechanisms of bone metastasis. $N$ Engl J Med 2004;350:1655-64.

7. Guise TA, Mohammad KS, Clines G, et al. Basic mechanisms responsible for osteolytic and osteoblastic bone metastases. Clin Cancer Res 2006;12:6213s-16s.

8. Body JJ, Bartl R, Burckhardt $\mathrm{P}$, et al. Current use of bisphosphonates in oncology. International Bone and Cancer Study Group. J Clin Oncol 1998;16:3890-9.

9. Bloomfield DJ. Should bisphosphonates be part of the standard therapy of patients with multiple myeloma or bone metastases from other cancers? An evidence-based review. J Clin Oncol 1998; $16: 1218-25$

10. Hitron A, Adams V. The pharmacological management of skeletalrelated events from metastatic tumors. Orthopedics 2009;32:188.

11. Leyland-Jones B. Pharmacokinetic and clinical equivalence of oral and intravenous ibandronate for metastatic bone disease. EJC Suppl 2004;2:9-12.

12. Body JJ, Diel IJ, Lichinitzer M, et al. Oral ibandronate reduces the risk of skeletal complications in breast cancer patients with metastatic bone disease: results from two randomised, placebo-controlled phase III studies. Br J Cancer 2004;90:1133-7.

13. Heras $\mathrm{P}$, Karagiannis $\mathrm{S}$, Kritikos $\mathrm{K}$, et al. Ibandronate is effective in preventing skeletal events in patients with bone metastases from colorectal cancer. Eur J Cancer Care (Engl) 2007;16:539-42.

14. Menssen HD, Sakalova A, Fontana A, et al. Effects of long-term intravenous ibandronate therapy on skeletal-related events, survival, and bone resorption markers in patients with advanced multiple myeloma. J Clin Oncol 2002;20:2353-9.

15. Zhu M, Liang R, Pan LH, et al. Zoledronate for metastatic bone disease and pain: a meta-analysis of randomized clinical trials. Pain Med 2013;14:257-64.

16. McDermott RS, Kloth DD, Wang $\mathrm{H}$, et al. Impact of zoledronic acid on renal function in patients with cancer: clinical significance and development of a predictive model. J Support Oncol 2006;4:524-9.

17. Cha YJ, Lee YJ. Risk factors for renal impairment in patients with solid tumors or multiple myeloma treated with zoledronic acid. Int $J$ Clin Pharmacol Ther 2013;51:274-82.

18. Joensuu TK. Renal toxicity following zoledronic acid reversed with ibandronate in a prostate cancer patient with bone metastases. Urol Int 2008;80:448-50.

19. Pecherstorfer M, Rivkin S, Body JJ, et al. Long-term safety of intravenous ibandronic acid for up to 4years in metastatic breast cancer: an open-label trial. Clin Drug Investig 2006;26:315-22.
20. Higgins JPT, Green S. Cochrane handbook for systematic reviews of interventions version 5.1.0 (updated March 2011). 2013.

21. Diel IJ, Body JJ, Lichinitser MR, et al. Improved quality of life after long-term treatment with the bisphosphonate ibandronate in patients with metastatic bone disease due to breast cancer. Eur J Cancer 2004;40:1704-12.

22. Heras $\mathrm{P}$, Kritikos K, Hatzopoulos A, et al. Efficacy of ibandronate for the treatment of skeletal events in patients with metastatic breast cancer. Eur J Cancer Care (Engl) 2009;18:653-6.

23. Coleman RE, Purohit OP, Black C, et al. Double-blind, randomised, placebo-controlled, dose-finding study of oral ibandronate in patients with metastatic bone disease. Ann Oncol 1999;10:311-16.

24. Francini F, Pascucci A, Bargagli G, et al. Effects of intravenous zoledronic acid and oral ibandronate on early changes in markers of bone turnover in patients with bone metastases from non-small cell lung cancer. Int J Clin Oncol 2011;16:264-9.

25. Choudhury KB, Mallik $\mathrm{C}$, Sharma $\mathrm{S}$, et al. A randomized controlled trial to compare the efficacy of bisphosphonates in the management of painful bone metastasis. Indian J Palliat 2011;17:210-18.

26. Body JJ, Lichinitser M, Tjulandin S, et al. Oral ibandronate is as active as intravenous zoledronic acid for reducing bone turnover markers in women with breast cancer and bone metastases. Ann Oncol 2007;18:1165-71.

27. Barrett-Lee $P$, Casbard A, Abraham J, et al. Oral ibandronic acid versus intravenous zoledronic acid in treatment of bone metastases from breast cancer: a randomised, open label, non-inferiority phase 3 trial. Lancet Oncol 2014;15:114-22.

28. Wong MH, Stockler MR, Pavlakis N. Bisphosphonates and other bone agents for breast cancer. Cochrane Database Syst Rev 2012; (2):CD003474

29. Yuen KK, Shelley M, Sze WM, et al. Bisphosphonates for advanced prostate cancer. Cochrane Database Syst Rev 2006;(18): CD006250.

30. Lopez-Olivo MA, Shah NA, Pratt G, et al. Bisphosphonates in the treatment of patients with lung cancer and metastatic bone disease: a systematic review and meta-analysis. Support Care Cancer 2012;20:2985-98.

31. Mhaskar R, Redzepovic J, Wheatley K, et al. Bisphosphonates in multiple myeloma: a network meta-analysis. Cochrane Database Syst Rev 2012;(5):CD003188.

32. Palmieri C, Fullarton JR, Brown J. Comparative efficacy of bisphosphonates in metastatic breast and prostate cancer and multiple myeloma: a mixed-treatment meta-analysis. Clin Cancer Res 2013;19:6863-72.

33. Sue-Ann M, David C, Robin M. Safety of oral ibandronate in the trement of bone metastases from breast cancer long-term follow-up experience. Clin Drug Invest 2006;26:43-8.

34. Luedders DW, Steinhoff J, Thill M, et al. Lack of difference in acute nephrotoxicity of intravenous bisphosphonates zoledronic acid and ibandronate in women with breast cancer and bone metastases. Anticancer Res 2015;35:1797-802. 